\title{
Synthetic Polymer Scaffolds for Soft Tissue Engineering
}

\author{
O. JANOUŠKOVÁ ${ }^{1}$ \\ ${ }^{1}$ Department of Biological Models, Institute of Macromolecular Chemistry of the Czech Academy \\ of Sciences, Prague, Czech Republic
}

Received May 31, 2018

Accepted July 11, 2018

\section{Summary}

Tissue engineering (TE) and regenerative medicine are progressively developed areas due to many novel tissue replacements and implementation strategies. Increasing knowledge involving the fabrication of biomaterials with advanced physicochemical and biological characteristics, successful isolation and preparation of stem cells, incorporation of growth and differentiation factors, and biomimetic environments gives us a unique opportunity to develop various types of scaffolds for TE. The current strategies for soft tissue reconstitution or regeneration highlight the importance of novel regenerative therapies in cases of significant soft tissue loss and in cases of congenital defects, disease, trauma and ageing. Various types of biomaterials and scaffolds have been tested for soft tissue regeneration. The synthetic types of materials have gained great attention due to high versatility, tunability and easy functionalization for better biocompatibility. This article reviews the current materials that are usually the most used for the fabrication of scaffolds for soft TE; in addition, the types of scaffolds together with examples of their applications for the regenerative purposes of soft tissue, as well as their major physicochemical characteristics regarding the increased applicability of these materials in medicine, are reviewed.

\section{Key words}

Synthetic 3D scaffolds • Soft tissue regeneration • Tissue engineering

\section{Corresponding author}

O. Janouskova, Department of Biological Models, Institute of Macromolecular Chemistry of the Czech Academy of Sciences, Heyrovského nám. 2, 16206 Prague 6, Czech Republic. E-mail: janouskova@imc.cas.cz

\section{Introduction}

In the 1990s, Langer and Vacanti first defined the term "tissue engineering" (TE) (Langer and Vacanti 1993). TE combines the fields of cell biology, biomaterial engineering and medicine to produce new functional tissues. The three main components that are required for the reconstitution or regeneration of damaged or diseased tissue are as follows: i) harvested cells from donor tissue; ii) biomaterial scaffolds, which support cell attachment, proliferation and/or differentiation, as well as possess sufficient physicochemical properties; and iii) chemical signals, such as cytokines and growth factors. The scaffolds play a major role in TE strategies. Three-dimensional (3D) scaffolds have been usually used to provide a structurally stable environment for tissue regeneration. A scaffold serves as an artificial extracellular matrix (ECM). A native ECM is a 3D network whose composition and structure interact with the cells and provide structural support, transfer mechanical forces and allow the transport of chemical signals.

Scaffold materials can be based on natural or synthetic polymers. They can be degradable or non-degradable, depending on the specific use. Natural polymers were among the first biodegradable scaffolds, which were clinically used for TE purposes (Dhandayuthapani et al. 2011), preferentially due to their better overall interaction with various cell types and lack of an immune response (Nair 2007). Synthetic polymers are largely studied and applied for TE. They were discovered to be cheaper and more easily functionalized than natural polymers, despite the potential for immune 
response or cytotoxicity depending on the used polymer materials and synthetic processes, which can include toxic substances. These types of polymers are highly useful in biomedical fields for their properties e.g. porosity, degradation time and mechanical characteristics. Desired properties can be tailored for specific applications. They can be produced under controlled conditions and in large uniform quantities. They exhibit predictable, reproducible, mechanical and physical properties such as strength, elastic modulus, and degradation rate. The synthetic polymer scaffolds are widely combined with natural polymers, naturally isolated proteins or peptides to improve, for example, hydrophobicity, cell attachment and biodegradability.

Materials for TE should have mechanical properties suitable for reconstructing or replacing damaged tissues. Moreover, the materials must be biocompatible, meaning that they are non-cytotoxic, do not cause excessive immune responses, must be capable of mimicking ECM, and provide an optimal support for cell adhesion and proliferation, facilitating cell-to-cell contact and cell migration. The materials should further be majorly bioabsorbable over the appropriate time frame, being necessary for replacement by growing tissue, and the materials must be adaptable to scaffold manufacturing techniques.

Soft TE has been developed as an advanced strategy to repair damage in soft tissue or diseased soft tissues in the case when the natural ability of the body to repair small or moderate sized tissue damage has failed, and the process of reparation remains the real problem. Soft tissue covers a variety of tissues, such as skin, tendon, muscle, cartilage, nerves, fascia, intervertebral disc or blood vessels. These tissues often have supporting or connecting functions of the body structures and organs. Frequently in everyday life, soft tissue damage caused by congenital defects, disease, trauma and ageing often leads to non-self-healable defects (Xu et al. 2014). Autologous implantation is the first method of treating the defects or disease. Unfortunately, it has been shown that autologous tissue can be easily absorbed, and only up to $60 \%$ of soft tissue cells remain viable (Bauer-Kreisel et al. 2010). In this view, the TE has been used to develop new biological substitutes to overcome barriers of current clinical treatments for repairing and regenerating damaged or diseased of soft tissues and organs.

This review is focused on providing an overview of the synthetic biomaterials used for scaffold fabrication for soft tissue reparation, the classification of the most prevalent type of scaffolds, their important physicochemical characterizations in regard to soft tissue engineering applications, and examples of experimental and clinical applications.

\section{Physicochemical characteristics of scaffolds}

Scaffolds serve as an active instrument to provide guidance for the formation of new tissue. Through known physicochemical properties and biological functions of damaged tissue, the scaffolds should be fabricated. The required characteristics are as follows:

1) External geometry, which influences interconnectivity

2) Porosity and pore size

3) Mechanical properties

4) Degradation properties

5) Biocompatibility and susceptibility to hosting cells

Surface properties such as surface area, charge, and chemical modification

\section{External geometry}

Scaffolds should mimic a natural ECM in damaged tissue in such a way as to provide structural support and tensile strength, offer an attachment site or cell surface receptors that later influence tissue formation, and finally initiate regeneration. The scaffolds are prepared from nano- to macro-scale structural geometry. In the geometry of scaffolds, the maintenance of highly interconnected porous fabrics of high surface density has to be addressed. This maintenance can favor the better infiltration of cells, growth and regenerative components of the scaffold.

\section{Porosity and pore size}

Porosity is one of the major factors for the appropriate ingrowth of cells and vascularisation. Pore size, pore distribution, pore volume, pore interconnectivity, pore shape, and pore wall roughness have to be addressed during the design of the scaffold. These pore properties are crucial for the growth of new tissues and their reorganization, which includes building up the cellular network and interconnected pathways for nutrient transportation, cell signalling and proliferation. The optimum pore sizes for neovascularization were demonstrated experimentally and were $5 \mu \mathrm{m}$ (Brauker et al. 1995), 5-15 $\mu \mathrm{m}$ for fibroblast ingrowth (Klawitter and Hulbert 1971), $20 \mu \mathrm{m}$ for hepatocyte ingrowth (Yang et al. 2001), or $20-125 \mu \mathrm{m}$ for regeneration of adult 
mammalian skin (Whang et al. 1999). It is also crucial to ensure the cells are approximately $200 \mu \mathrm{m}$ from the blood supply to provide sufficient oxygen and nutrient transfer (Yang et al. 2001). In addition to appropriate porosity, the mechanical strength of the scaffolds has to be retained.

\section{Mechanical properties}

The biostability of many scaffolds relies on factors such as strength, elasticity, and absorption at the material interface and given the chemical degradation of the material. These properties have to encourage the regeneration of the tissue. The biomaterial scaffold should also temporarily resist and conduct the loads and stresses that the new tissue can ultimately bear. It is important to evaluate rheological parameters, such as i) elastic modulus - measured strain in response to a given compressive stress along the force; ii) flexural modulus measured relationship between a bending stress and the resulting strain; iii) tensile strength - maximum stress that the material can withstand before it breaks; and iv) maximum strain - ductility of a material or total stein exhibited prior to fracture. The reparation tissue requires different mechanical conditions, based on the natural properties of the appropriate tissue. These are crucial for mimicking using biomaterial scaffolds. Wegst and Ashby (2004) published the diagrams of diversity of mechanical properties necessary for mimicking the natural tissues and materials. The major factors affecting the mechanical properties and structural integrity of the scaffolds are altered by various pore volumes, sizes, shapes, orientations and connectivity. The elasticity of the scaffold matrix play also crucial role with very strong effects on the cell morphology, transcript profiles, marker proteins, and the stability of cell responses.(Engler et al. 2006, Buxboim et al. 2010).

\section{Degradation rate}

Scaffold degradation can occur through physical or chemical processes and/or biological processes that are mediated by biomolecules such as enzymes. Biodegradation of polymeric materials involves cleavage of hydrolytically or enzymatically sensitive bonds in a polymer. The degradation rate of a polymer depends mainly on the properties of the polymer, including the chemical structure, the presence of hydrolytically unstable bonds, the level of hydrophilicity or hydrophobicity, crystalline or amorphous morphology, the copolymer ratio or the molecular weight (Ye et al.
1997). The biodegradable scaffold degrades by predetermined periods of time to be replaced by newly developed tissue. During the degradation, the polymeric scaffolds breakdown the internal structure and thus reduce the molecular mass. The non-biodegradable polymer scaffolds stay biologically stable and can provide permanent support in the patients; e.g. poly(methylmethakrylate) (PMMA) is usually used as bone cement in hip or knee replacements (Ramakrishna et al. 2001).

\section{Biocompatibility}

Biocompatibility in general means that the material should result in beneficial cellular or tissue response and finally optimize the clinically relevant performance of the therapy, without creation of any undesirable local or systemic effects in the recipient. The biocompatibility of a scaffold for TE refers to the ability to be a matrix that will support cellular activity, including the facilitation of molecular and mechanical signalling systems. Some important factors in view of scaffold biocompatibility are chemistry, structure and morphology. Polymers such as polylactide (PLA), polyglycolide (PGA), poly-(l-lactide-co-glycolide) PLGA, or polycaprolactone (PCL) belong among the recently studied and used biocompatible polymers. The behaviour of the cells - e.g. adsorption and proliferation on polymeric materials depends on surface characteristics such as wettability, hydrophilicity/hydrophobicity, chemistry, surface charge/charge distribution or rigidity and roughness. Many surface modifications are used to optimize the desired biocompatibility of prepared scaffolds (Hejcl et al. 2013, Elbert and Hubbell 1996).

\section{Surface properties}

The surface of the scaffold is the primary site of interaction with surrounding cells and tissue. The surface includes both chemical and topographical characteristics. Scaffolds with a large and accessible surface area are favorable. The surface properties can be selectively modified to optimize and increase material for hosting the cells. The surface can be functionalized using biological or chemical factors. It can increase multifunctionality and mechanical properties but mainly biocompatibility; therefore, cells can specifically recognize scaffolds or increase proliferation, ingrowth or differentiation. Mechanically, scaffolds can be optimized by, for example, natural fibrils. Modification using adhesive proteins such as collagen, fibronectin, RGD peptide, 
growth factors (e.g. bFGF and EGF), and insulin mainly alters biocompatibility. These factors can be covalently attached, electrostatically adsorbed or self-assembled on the biomaterial surface to develop brand new materials (Elbert and Hubbell 1996).

\section{Polymeric materials}

Among the synthetic polymers, PCL, poly (L-lactic acid) (PLLA), PLGA or PGA are currently the most popular for the creation of 3D scaffolds (Stratton et al. 2016, Kim et al. 2011).

\section{Polycaprolactone}

Polycaprolactone $(P C L)$ is a bioresorbable polyester material, first synthesized in the 1930s. PCL is semicrystalline polyester. It is considered to be both a soft and hard tissue compatible material (Malikmammadov et al. 2018). PCL is elastic in comparison to other polyesters, and it is used in various forms such as films, fibers or microparticles. It has a relatively slow degradation rate (2-4 years). PCL is degraded under physiological conditions by the hydrolysis of its ester linkages (Shimao 2001). It has strong solubility and blend compatibility with other biomaterials (Okada 2002). Several copolymers have been investigated for their potential to control the degradation of PCL, e.g. PLLA and poly-(N-2(hydroxypropyl) methacrylamid) HPMA. The degradation periods of PCL copolymers with other rapidly degraded materials can vary from months to years (Hyun et al. 2006). PCL also has poor cellular adhesion properties on its own, without some form of functionalization. Approaches to improving its bioactivity include copolymerization, surface functionalization, or blend formations (Yoo et al. 2009, Ghasemi-Mobarakeh et al. 2010). Porous PCL scaffolds have been demonstrated to maintain the native phenotypes as chondrocytes within cartilage tissue (Stratton et al. 2016, Calikoglu Koyuncu et al. 2015). This finding demonstrated the applicability of porous PCL scaffolds for tissue engineering and their ability to mimic the native tissue environment and capacity for the functionalization of PCL scaffolds for better bioactivity.

\section{Poly (L-lactic acid)}

Poly (L-lactic acid) (PLLA) is a synthetic biodegradable polyester formed from the polymerization of L-lactide. PLLA belongs to group of saturated poly-a- hydroxy esters. PLLA is one of the three found forms of PLA, the two others are poly (D-lactic acid) and poly (DL-lactic acid). PLLA has a wide variety of applications e.g. prosthetics, vascular grafts, skin regeneration scaffolds or bone screws (Stratton et al. 2016). PLLA degrades into nontoxic by-products and can easily be combined with other materials. However, PLLA has a faster degradation rate in comparison with PCL, and it still has a relatively low degradation rate in comparison with the rates of other materials for tissue engineering. The degradation products of PLLA show high crystallinity, which can lead to lower biocompatibility. To resolve this issue the PLA can be fabricated as a combination of L-lactic acid and D-lactic acid, which degrade more rapidly, lack the high crystallinity and shows greater biocompatibility (Fukushima and Kimura 2008). There are a few PLLA materials that are already FDA approved, e.g. injectable Sulptura TM, which is currently used to treat facial atrophy (Attenello and Maas 2015).

\section{Poly(DL lactic acid-co-glycolic acid)}

Poly (DL lactic acid-co-glycolic acid) (PLGA) is the copolymer of lactic and glycolic acids. PLGA is among the most widely used synthetic polyesters for scaffold formation in tissue engineering applications (Li et al. 2002, Stratton et al. 2016). The major advantages of PLGA are biodegradability, adaptability and customization of different types of formulations or surface modifications. PLGA has improved polymer biochemical properties such as faster and more controllable biodegradation rate compared to pure monomers. Increasing ratio of PGA can influence the rapidity of PLGA degradation. PLGA can be dissolved in a wider spectrum of common solvents in comparison with PLA or PGA. The solubility increase with higher ratio of PLA. The majority of PLGAs are amorphous rather than crystalline, which allows easier access to water and therefore faster degradation. PLGA scaffolds are degraded under normal physiological conditions, with degradation rates that vary depending on the copolymers and produced monomers - lactic acid and glycolic acid, which are nontoxic natural by-products of metabolic pathways. The local environment factors also play important roles in the degradation process. One major limitation in its bioactivity is its acidity towards the degradation products; this acidity can, in large quantities, be difficult for rapid metabolization by the body. To resolve this issue the scaffolds can be fabricated with 
greater amount of PGA in the scaffold material, which leads to a slower degradation rate and less acidic by-products. PLGA is an FDA approved, commercially available material; one example is Osteofoam ${ }^{\mathrm{TM}}$ for bone regeneration (Ishaug et al. 1997).

\section{Polyethylene glycol-based polymers}

Polyethylene glycol-based polymers (PEG) also known as poly (ethylene oxide) (PEO) is a non-ionic, biocompatible material with optimal physicochemical and biological properties in view of biomedical applications. PEG is minimally immunogenic after implantation. PEG is mainly used in the form of hydrogels for scaffold preparations. Hydrophilic PEG hydrogel scaffolds can be produced through a variety of cross linking methods (Zhu and Marchant 2011). The selected crosslinking process can influence the physicochemical properties of scaffolds, such as permeability, molecular diffusion, elasticity, modulus or degradation rate. Chemical modification of PEG scaffolds can lead to better biological properties. PEG-PPG block copolymers are FDA approved and serve as injectable scaffolds e.g. Poloxamers ${ }^{\mathrm{TM}}$ (Lee et al. 2003).

\section{Other synthetic biomaterials}

Poly (ethylene terephthalate) (PET) is a thermoplastic polymer made by polycondensation of ethylene glycol with either terephthalic acid or dimethyl terephthalate. PET are frequently found in medical applications, due to their unique chemical and physical properties. PET was first commercialized by DuPont in 1930 as Dacron. The physical properties of PET are largely determined by the degree of crystallinity. PET are successfully used in pathology of large diameter arteries and combination with other materials e.g. gelatine for increase treatment of small diameter blood vessels (Puskas and Chen 2004, Ma et al. 2005).

Poly (propylene fumarate) (PPF) is used to increase the hydrophobicity of PLA, PGA or PCLIt is a linear polyester, which has repeating units containing ester bonds. The hydrolysis of the ester bonds allows PPF to degrade. PPF is clearly modified by PCL or PEG to develop PCL fumarate and PEG fumarate. These polymers have been studied as injectable scaffolds (Tan and Marra 2010).

Poly vinyl alcohol (PVA) is a highly hydrated, water soluble synthetic polymer, which forms crystallizing hydrogels. PVA hydrogels show a reduced protein-binding tendency, relatively higher elasticity and water content. FDA has approved PVA to be in close contact with food products. In medical devices, PVA is used as a biomaterial due to its biocompatible, nontoxic, noncarcinogenic, swelling properties, and bioadhesive characteristics. Some of the most common medical uses of PVA are in soft contact lenses, eye drops, embolization particles, tissue adhesion barriers, and as artificial cartilage and meniscus. (Baker et al. 2012). PVA hydrogels have been also evaluated in combination with alginate as a scaffold for tissue engineering (Liu et al. 2017, Stratton et al. 2016).

Poly (amino-amine) (PAA) is a family of synthetic, branched, spherical polymers. PAA is highly versatile due to the presence of side groups that can be substituted for functional end groups e.g. - $\mathrm{NH} 2,-\mathrm{COOH}$ or $-\mathrm{OH}$ to modify the polymer biocharacteristics. PAA are highly hydrophilic and are able to degrade in waterbased solutions to nontoxic by-products.

Polyurethans (PU) are elastic materials, and their desirable properties include durability, fatigue resistance, non-immunogenicity and good tolerance during healing process. For these properties, PU are used for development of bio- or blood compatible materials (Petrović and Ferguson 1991). PU are used in combination with other materials for supporting cell attachment, proliferation and healing. One of their disadvantages is limited stability in vivo, which can be overcome by functionalization (Jóźwiak et al. 2008).

Poly (2-hydroxyethyl methacrylate and 2-hydroxyethyl methacrylate-co-methyl methacrylate) (PHEMA/PHEMA-MMA)-based polymer hydrogel scaffolds have the disadvantage of being nonbiodegradable (Tsai et al. 2006). Nevertheless, this property allows them high stability upon implantation. In addition, these are biocompatible hydrogels, with the capacity of swelling in water and retaining significant amounts of water without dissolving. PHEMA polymers are the most actively researched non-degradable materials used for nerve guidance channels (Dalton et al. 2002, Straley et al. 2010) because they possess soft, tuneable mechanical properties and easy formation of tubular shapes with controlled dimensions, morphology, and permeability (Dalton et al. 2002).

Poly (N-2-(hydroxypropyl) methacrylamide) (PHPMA) hydrogels were first described by Woerly and colleagues (Woerly et al. 1998). The porous structure of PHPMA allows the transport of both small and large molecules, as well as the migration of cells and blood vessels (Woerly et al. 1999). This type of hydrogel also 
presents viscoelastic properties similar to the neural tissue and shows permisivity to the growth of a reparative tissue composed of glial cells, blood vessels, axons, and dendrites (Woerly et al. 1999).

\section{Type of scaffold structure}

\section{Nanofibers}

Nanofibers are widely used due to their properties to mimic the architecture of natural human tissue at the nanometer scale. Nanofibers are usually fabricated using electrospinning (Nayak et al. 2012). The nanofibers support cell adhesion efficiently due to the higher surface-to-volume ratio, and microporous structures efficiently support the cell adhesion, proliferation, migration and differentiation and have greater mechanical strength than fibers (Subbiah et al. 2005). They have been prepared from synthetic and natural materials. Fibers can be oriented randomly or aligned. The major differences between them are the mechanical properties, mainly altered stiffness and resistance in all directions to mechanical testing for random fibers in contrast to aligned fibers, which have strong mechanical properties in the one direction. Thus, aligned nanofibers are more often fabricated for tendon or ligament regeneration, peripheral nerve regeneration or skeletal muscle application, but random nanofibers are therefore useful for skin and cartilage regeneration applications. Aligned nanofibers can be used to specify the direction of tissue growth. The PLA, PU, PCL, PLGA, PLLA or PLLA-PCL is often used for fibrous scaffold fabrication. Examples of PLLA nanofibers are shown in Figure 1. The PLLA nanofibers preparation by electrospinning and isolation of pig retina epithelial cells (RPE) for the seeding of the nanofibers was previously describe by Popelka et al. (2015) The nanofibers was used for the cultivation of RPE cells. The cells were visualized by light microscopy after $72 \mathrm{~h}$ of incubation (unpublished data). Most of the polymer nanofibers must be specifically functionalized for successful applications. The easiest modification methods are physical blending and coating. Surface grafting polymerization has also been used for attaching ligand molecules and adhesive proteins on nanofiber surface. The properties of nanofibers have been used for neurite development of dorsal root ganglia explants, which were seeded onto uniformly aligned electrospun PLA nanofibers (Corey et al. 2007). Other examples are the PVA random fibrous scaffolds with chondroitin sulphate, which have been shown to enhance mesenchymal stem cell chondrogenic differentiation in vitro and enhance the reparation of cartilage injury in vivo (Coburn et al. 2012).
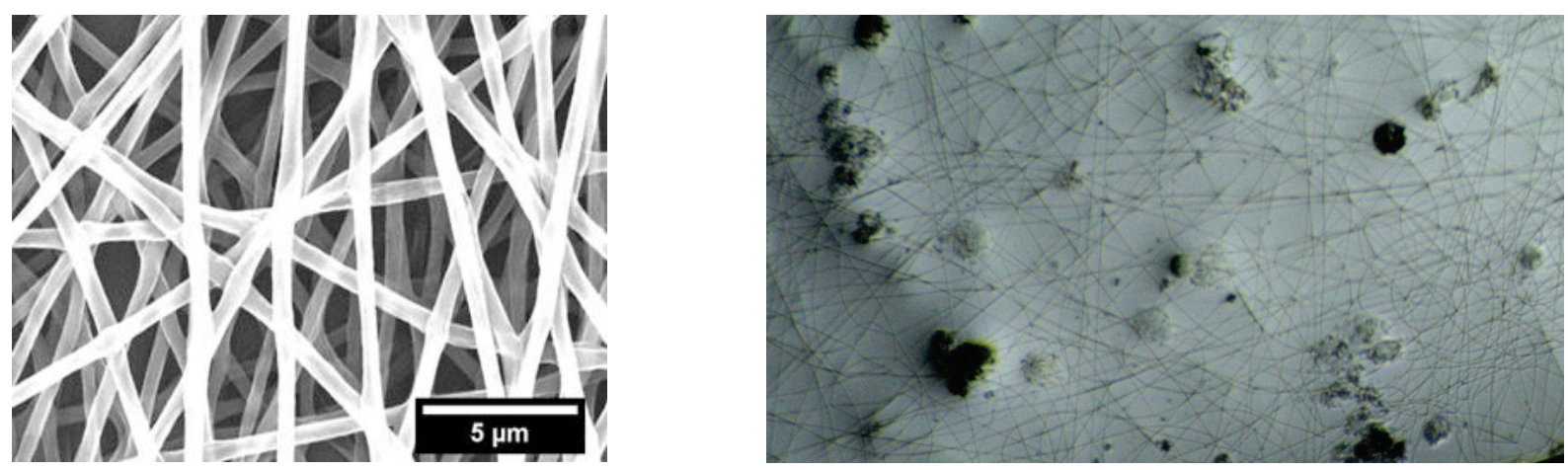

Fig. 1. (A) Scanning electron microscopy of PLLA nanotubes prepared by electrospinning; (B) light microscopy of the same PLLA nanotubes seeded with freshly isolated pig retina epithelium cells (unpublished data).

\section{Hydrogels}

Hydrogels are water-absorbing hydrophilic and highly flexible polymeric materials. They are favorable for promoting cell migration, angiogenesis, high water content, and rapid nutrient diffusion. The gels are formed when the network is covalently crosslinked. The criteria for hydrogel scaffolds are similar to other types of scaffolds designed for tissue engineering. They have to keep appropriate physicochemical parameters such as degradation and mechanics or biological parameters such as cell adhesion. The degradation rates of tissue scaffolds should be matched to the rate of various cellular processes to optimize tissue regeneration. Major advantages of hydrogels in view of tissue engineering include structural similarities to native ECM and a potential for drug or growth factor delivery (AssunçãoSilva et al. 2015, Jin and Dijkstra 2010, Sirc et al. 2015). Some disadvantages of hydrogels are relative mechanical 
weaknesses due to their water content, which could be up to $90 \%$, and inefficient attachment of cells without further modifications (Hoffman 2012). A wide spectrum of synthetic materials can be used for hydrogels fabrication e.g. PLA, PPF-derived copolymers, PEG-derivatives, PAA, PEO, PVA, or HEMA, HPMA, and various polypeptides (Lee and Mooney 2001). Figure 2 shows laser scanning confocal microscopy (LSCM) of PHPMA-based hydrogels. Their preparation was described by Hejcl et al. (2013). Rat mesenchymal stem cells (rMSC) were seeded on the hydrogels and cultivated for five days. Then the cells were visualized by

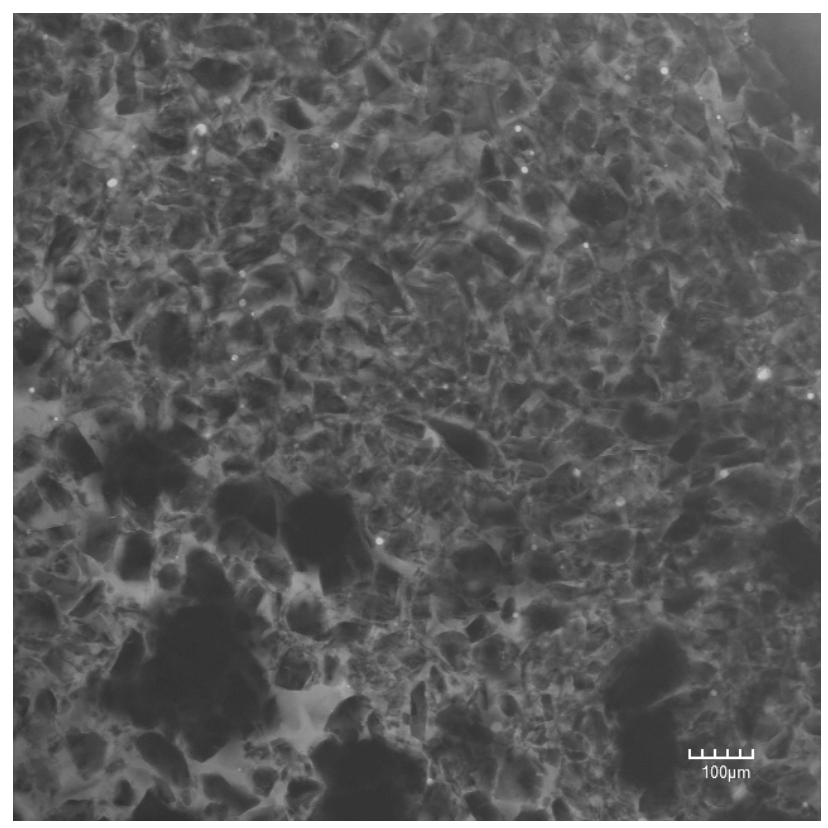

nuclei labeling using Hoechst 33342. Hydrogel was visualized by experimentally determine labeling with CellMask $^{\mathrm{TM}}$ Green Plasma Membrane Stain. (unpublished data) Hydrogels can be functionalized with various peptide sequences to increase cell attachment, growth and differentiation e.g. using RGDS such as peptides (Bracher et al. 2013, Hejcl et al. 2013, Golunova et al. 2015) or growth factors for drug delivery applications (Guadalupe et al. 2015). Hydrogels are currently studied for their use in cartilage wound healing, neuronal tissue regeneration or replacement of connective tissues (Dhandayuthapani et al. 2011).

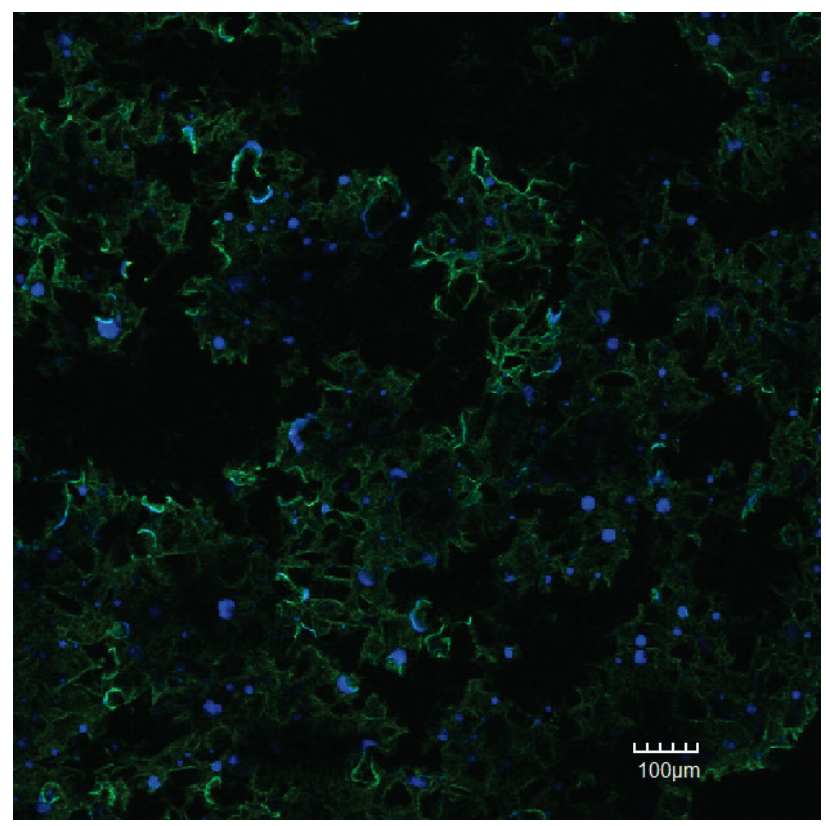

Fig. 2. (A) (LSCM) of PHPMA-based hydrogels developed by thermic polymerization, as a porogen - NaCl was used. (B) LSCM of PHPMA-based hydrogels after five days of rMSC growth. Hydrogel (green) was labelled by a CellMask ${ }^{T M}$ Green Plasma Membrane Stain (Thermo Fischer Scientific, Czech Republic). The cells were visualized by labelling the nuclei (blue) using Hoechst 33342. (unpublished data).

\section{D-printed structure}

Currently, 3D printing is increasing the applications of tissue engineering. Biocompatible materials could be printed as 3D scaffolds using various algorithms (Rengier et al. 2010) with possibilities to set up ranges from millimeters to the nanoscale. Threedimensional printing offers advantages over traditional techniques such as porogen leaching or enhanced productivity. Some drawbacks of cell viability are coupled with this methodology. One of the problems is achieving biologically relevant cellular densities due to the necessity of the transformation of biological material into liquid form for the printing. It is applied to both hard and soft tissue engineering. The $3 \mathrm{D}$ printing was used to fabricate and transplant soft tissue, e.g. multilayered skin, vascular grafts, tracheal splints, heart tissue or cartilage structures (Murphy and Atala 2014, Jakus et al. 2016).

\section{Microparticles}

Although microparticles have been initially developed as a carrier for drug encapsulation (Berkland et al. 2004), their unique properties are utilized for the delivery of growth factors in a controlled fashion in TE applications (Brannon-Peppas 1995). Microparticle scaffolds offer several benefits, including easy fabrication, control over morphology and versatility in terms of controlling the release of encapsulated factors. They can be embedded into 3D scaffolds, and they have 
been shown to cumulatively release growth factors or drugs ( $\mathrm{Hu}$ et al. 2001). They have also been used as injectable scaffolds. The applications are demonstrated mostly in bone tissue regeneration. PLGA microsphere scaffolds demonstrated the potential of the porous microsphere matrix to be used as a scaffold for bone tissue engineering (Borden et al. 2002). Recently, the use of lovastatin - PU particle scaffolds has been demonstrated, being able to release lovastatin and enhance bone regeneration defects in rats (Yoshii et al. 2014).

\section{Examples of synthetic scaffolds applications}

\section{Nerve regeneration}

Nerve regenerative applications have to address the difference between the central nervous system (CNS) and the peripheral nervous system (PNS) (Horner and Gage 2000, Scheib and Höke 2013). The CNS consists of the brain and spinal cord, and the PNS consists of the ganglia and nervous tissue outside of the CNS. Serious problems for the evaluation of new materials are missing in in vivo models because the nerve axons in mice, the most prevalently used animals for in vivo testing, are smaller and shorter; accordingly, the natures of atrophy and damage recovery behave differently in mice compared to humans. Thus, rats and larger animals have to be used for these purposes to evaluate the efficacy of the materials for TE in vivo. In view of the regeneration of the PNS, Schwan cells are mostly studied for this application. They provide structural support and participate in the myelination of axons. The $3 \mathrm{D}$ scaffolds have to serve as structural support for axons via Schwann cells and promote myelination and outgrowth of neuronal cells. For these purposes, the nanofibers are largely applicable, mainly when they are designed to guide the axonal outgrowth of neurits. Of major importance to nerve regeneration are nerve guidance conduits, which are important in directing the growth of axons from one proximal nerve end and helping to reduce inhibitory scar tissue at the site of injury, as well as in secreting growth factors that can support regeneration (Anderson et al. 2015).

There are variety of different biomaterials approved for clinical use to guide artificial nerve conduits, such as PGA, poly-DL-lactide-co-caprolactone (PLCL), and PVA. Many factors influence the choice of materials, as the degradation rate, swelling, biocompatibility, and possibility of the incorporation of proteins or neurotrophic factors in the ECM can increase the adhesion and growth potential of cells (Nectow et al. 2012). One of the most successful materials for nerve regeneration has been observed in PGA (Schlosshauer et al. 2006). PCL nanofibers were also experimentally studied. These nanofibers were able to allow the growth of neurites when pre-seeded with Schwan cells and moderately recover the functionality of a $14 \mathrm{~mm}$ rat sciatic nerve injury model in vivo (Xie et al. 2014). The combination of synthetic nanofibers or other type of scaffolds, such as hydrogels with natural proteins including fibroin, elastin or laminin, has been shown to significantly increase the extension of nerite or Schwann cells in vitro, stimulate the outgrowth of nerve axons and improve nerve functional recovery (Sedaghati et al. 2011, de Luca et al. 2014). Hydrogels have also been studied as scaffolds for nervous system regeneration. The main advantages of hydrogels are stiffness, tuning of pore size, swelling, the possibility to functionalize the synthetic materials with growth factors, adhesion molecules and factors that inhibit the development of scar tissue at the site of an injury. The natural and synthetic polymers in the form of injectable hydrogels were used to study spinal cord injury, regeneration of the CNS and peripheral nerve regeneration (Pakulska et al. 2012). The hydrogels based on PEG, PHPMA, PHEMA are also studied in combination with stem cells to regenerate axonal growth (Assunção-Silva et al. 2015). The softer hydrogels as material for culturing neural stem cells have been reported to allow for differentiation into astrocytes and neurons, while stiffer hydrogels tends to allow for differentiation into oligodendrocytes (Leipzig and Shoichet 2009).

\section{Muscle regeneration}

Muscle regeneration presents a very difficult challenge for TE due to the requirements for scaffold properties, which have to keep structural integrity together with contractility and force regeneration. Between the three types of muscle tissue - cardiac, smooth and skeletal - the cardiac muscle regeneration is of particular importance due to limited regeneration capabilities in mammals. Cardiomyocytes play a major role in the regeneration of cardiac muscle. They are capable of differentiating into basic structures for cardiac tissues. For this purpose, the lot of natural polymers and also PGA were evaluated (Masuda et al. 2008, Kaiser and Coulombe 2015). Modification of the scaffolds using RGD peptide can enhance cellular adhesion and 
accelerate tissue regeneration. The functionalization of cellular adhesion molecules with vitronectin and fibronectin serves similarly to RGD peptides (Nikolovski and Mooney 2000). Scaffolds made from the nanofibers of PCL and collagen have been evaluated for smooth muscle tissue engineering. The growth of cells were directed by nanofiber orientation, and the cells were able to maintain a typical phenotype shape (Venugopal et al. 2005). Skeletal muscle has a massive capacity for regeneration without external intervention. Muscle tissue is constantly being destroyed, repaired and remodelled. Although in the case of very hard injury, the regeneration capacity could be limited or lost. In the regeneration of skeletal muscle, the satellite cells play an important role in migration to the site of injury, proliferate and restore functional properties. Popular biomaterials as scaffolds for the regeneration of skeletal muscle tissue are hydrogels or fibrous meshes. In the development of regenerative methods based on various scaffolds for muscle tissue engineering, electrical stimulation was shown to support better differentiation potential of muscle precursor cells (Serena et al. 2008).

\section{Tendon and ligament regeneration}

Tendon and ligament injuries are quite common injuries of connective tissue. Surgical repair is the most commonly used method but often leads to degeneration of the frayed tissue (Jennings and Sefton 2002). Tendons do not naturally regenerate very well after even minor injuries. Hence, 3D scaffolds are of major importance for regeneration purposes. The $3 \mathrm{D}$ scaffolds must provide a suitable bio-environment and adequate mechanical properties such as elastic modulus, toughness and ultimate strength. The natural grafts often fail to bring back the mechanical and structural properties of the original tissue. The ECM of tendons is mostly composed of collagen type $\mathrm{I}$, and it is a relatively complex environment that is difficult to replicate. The synthetic materials offer a better performance in creating a suitable mechanical environment, e.g. PU/PET fibers obtained the adequate mechanical properties to alternate tendons and ligaments (De Santis et al. 2004). The other examples are PLGA/silk scaffolds, which demonstrate strong mechanical properties. PLGA fibers were used to release the bFGF, and microfibrous silk was used as reinforcement. After this scaffolds application, the increased gene expression of ligament and tendon ECM proteins have also been shown. The collagen production was increased (Sahoo et al. 2010). It was also demonstrated that PLGA, as a support for bone marrow stromal cells, stimulates the expression of collagen type I and helps to repair the in vivo defects in the Achilles tendon of rabbits (Yang et al. 2013). The major attention in ligament TE is given to the anterior cruciate ligament (ACL), which stabilizes the knee, because of its poor healing capabilities. For the reconstitution of ACL, the PLLA combined with silk fibers has been tested to mimic the natural mechanical properties and to deliver growth factors (Nau and Teuschl 2015). The mechanically strong PLLA nanofibers combined with flexible PCL nanofibers have also been tested for ACL regeneration. This material was able to release growth factors and support the proliferation of human mesenchymal stem cells (hMSC), and regenerative tissues express critical ligament markers (Laurilliard et al. 2015).

\section{Cartilage regeneration}

Cartilage tissue is often harmed in everyday life and cannot be completely self-healed. The evaluated materials have to meet the necessary critical requirements of mechanical strength and structural resilience. Polymer scaffolds used for cartilage regeneration tend to be fabricated from flexible biomaterials that can hold compression together with a supporting environment for chondrocytes. The most popular are natural scaffolds composed from collagen or hyaluronic acid seeded with autologous chondrocytes to treat the cartilage defects (Kim et al. 2011). PGA, PLLA and PLGA have been evaluated in vitro and in vivo for cartilage tissue regeneration (Moran et al. 2003, El Sayed et al. 2013, Sato et al. 2004). Among many studies, very promising results have been observed by Agrawal et al. (Agrawal et al. 2013). They design elastomeric fiber-reinforced hydrogel composites to achieve a cartilage-like structure by impregnating elastic PU fibers that had been arranged into hydrogels from PEG diglycidyl ether. They showed that the fibers could provide the strength and elasticity of the scaffold to closely mimic natural cartilage tissues. In addition, resorbable PGA fibers reinforced with PLGA scaffolds have been shown to possess optimal mechanical strength, improve pore size and morphology and be suitable for the proliferation of chondrocytes (Pei et al. 2017). Scaffolds made from a copolymer of PGA/PLA and polydioxanone were evaluated for the treatment of post-traumatic and degenerative cartilage defects in a group of 40 patients over 2 years. This treatment seems to be an effective option for the regeneration of many types of defects of the knee (Ossendorf et al. 2007). 


\section{Conclusions}

In summary, TE is a progressively developed interdisciplinary field that addresses the challenges in soft tissue repair, namely, of the reparation and regeneration of particular types of tissue after damages that are not possible to treat using classical medical approaches. Rising interest in the synthetic materials are mainly due to the development of new fabrication technologies, advanced architecture or combining various materials to produce polymeric scaffolds that meet certain design parameters to be useful for mimicking ECM in appropriate tissues. The essential factors that point out the progress in the field of soft TE include increases in the understanding of chemical and biological factors, which influence the attachment, growth or differentiation of appropriate cells and allow successful tissue reconstitution. The increasing knowledge of the tissue necessities and appropriate cell behaviour is extremely favorable. Although the numbers of polymeric scaffolds are under intensive research and many of them are commercially available and clinically applicable, the successful transition of regenerative medicine through TE technologies will require collaboration among material, pharmaceutical, biological and clinical experts.

\section{Conflict of Interest}

There is no conflict of interest.

\section{Acknowledgements}

This work was supported by the Ministry of Education, Youth and Sports of CR within the National Sustainability Program I (NPU I), Project POLYMAT LO1507.

\section{References}

AGRAWAL A, RAHBAR N, CALVERT PD: Strong fiber-reinforced hydrogel. Acta Biomater 9: 5313-5318, 2013.

ANDERSON M, SHELKE NB, MANOUKIAN OS, YU X, MCCULLOUGH LD, KUMBAR SG: Peripheral nerve regeneration strategies: electrically stimulating polymer based nerve growth conduits. Crit Rev Biomed Eng 43 : $131-159,2015$.

ASSUNÇÃO-SILVA RC, GOMES ED, SOUSA N, SILVA NA, SALGADO AJ: Hydrogels and cell based therapies in spinal cord injury regeneration. Stem Cells Int 2015: 948040, 2015.

ATTENELLO NH, MAAS CS: Injectable fillers: review of material and properties. Facial Plast Surg 31: 29-34, 2015.

BAKER MI, WALSH SP, SCHWARTZ Z, BOYAN BD: A review of polyvinyl alcohol and its uses in cartilage and orthopedic applications. J Biomed Mater Res B Appl Biomater 100: 1451-1457, 2012.

BAUER-KREISEL P, GOEPFERICH A, BLUNK T: Cell-delivery therapeutics for adipose tissue regeneration. $A d v$ Drug Deliv Rev 62: 798-813, 2010.

BERKLAND C, KIM K, PACK DW: Precision polymer microparticles for controlled-release drug delivery. In: ACS Symposium Series, Vol. 879 - Carrier-Based Drug Delivery. SVENSON S (ed.), American Chemical Society, Washington, 2004, pp 197-213.

BORDEN M, ATTAWIA M, KHAN Y, LAURENCIN CT: Tissue engineered microsphere-based matrices for bone repair: design and evaluation. Biomaterials 23: 551-559, 2002.

BRACHER M, BEZUIDENHOUT D, LUTOLF MP, FRANZ T, SUN M, ZILLA P, DAVIES NH: Cell specific ingrowth hydrogels. Biomaterials 34: 6797-6803, 2013.

BRANNON-PEPPAS L: Recent advances on the use of biodegradable microparticles and nanoparticles in controlled drug delivery. Int J Pharm 116: 1-9, 1995.

BRAUKER JH, CARR-BRENDEL VE, MARTINSON LA, CRUDELE J, JOHNSTON WD, JOHNSON RC: Neovascularization of synthetic membranes directed by membrane microarchitecture. J Biomed Mater Res 29 : 1517-1524, 1995.

BUXBOIM A, IVANOVSKA IL, DISCHER DE: Matrix elasticity, cytoskeletal forces and physics of the nucleus: how deeply do cells 'feel' outside and in? J Cell Sci 123: 297-308, 2010.

CALIKOGLU KOYUNCU AC, GUREL PEKOZER G, RAMAZANOGLU M, TORUN KOSE G, HASIRCI V: Cartilage tissue engineering on macroporous scaffolds using human tooth germ stem cells. J Tissue Eng Regen Med 11: 765-777, 2015. 
COBURN JM, GIBSON M, MONAGLE S, PATTERSON Z, ELISSEEFF JH: Bioinspired nanofibers support chondrogenesis for articular cartilage repair. Proc Natl Acad Sci U S A 109: 10012-10017, 2012.

COREY JM, LIN DY, MYCEK KB, CHEN Q, SAMUEL S, FELDMAN EL, MARTIN DC: Aligned electrospun nanofibers specify the direction of dorsal root ganglia neurite growth. $J$ Biomed Mater Res A 83: 636-645, 2007.

DALTON PD, FLYNN L, SHOICHET MS: Manufacture of poly(2-hydroxyethyl methacrylate-co-methyl methacrylate) hydrogel tubes for use as nerve guidance channels. Biomaterials 23: 3843-3851, 2002.

DHANDAYUTHAPANI B, YOSHIDA Y, MAEKAWA T, KUMAR DS: Polymeric scaffolds in tissue engineering application: a review. Int J Polym Sci 2011: 290602, 2011.

ELBERT DL, HUBBELL JA: Surface treatments of polymers for biocompatibility. Annu Rev Mater Sci 26: 365-394, 1996.

ENGLER AJ, SEN S, SWEENEY HL, DISCHER DE: Matrix elasticity directs stem cell lineage specification. Cell 126: 677-689, 2006.

FUKUSHIMA K, KIMURA Y: An efficient solid-state polycondensation method for synthesizing stereocomplexed poly(lactic acid)s with high molecular weight. J Polym Sci Part A Polym Chem 46: 3714-3722, 2008.

GHASEMI-MOBARAKEH L, PRABHAKARAN MP, MORSHED M, NASR-ESFAHANI MH, RAMAKRISHNA S: Bio-functionalized PCL nanofibrous scaffolds for nerve tissue engineering. Mater Sci Eng C 30: 1129-1136, 2010.

GOLUNOVA A, JAROŠ J, JURTÍKOVÁ V, KOTELNIKOV I, KOTEK J, HLÍDKOVÁ H, STREIT L, HAMPL A, RYPÁČEK F, PROKS V: N-(2-hydroxypropyl) methacrylamide based cryogels - synthesis and biomimetic modification for stem cell applications. Physiol Res 64 (Suppl 1): S19-S27, 2015.

GUADALUPE E, RAMOS D, SHELKE NB, JAMES R, GIBNEY C, KUMBAR SG: Bioactive polymeric nanofiber matrices for skin regeneration. J Appl Polym Sci 132: 41879, 2015.

HEJCL A, RUZICKA J, KAPCALOVA M, TURNOVCOVA K, KRUMBHOLCOVA E, PRADNY M, MICHALEK J, CIHLAR J, JENDELOVA P, SYKOVA E: Adjusting the chemical and physical properties of hydrogels leads to improved stem cell survival and tissue ingrowth in spinal cord injury reconstruction: a comparative study of four methacrylate hydrogels. Stem Cells Dev 22: 2794-2805, 2013.

HOFFMAN AS: Hydrogels for biomedical applications. Adv Drug Deliv Rev 54: 3-12, 2012.

HORNER PJ, GAGE FH: Regenerating the damaged central nervous system. Nature 407: 963-970, 2000.

HU Y, HOLLINGER JO, MARRA KG: Controlled release from coated polymer microparticles embedded in tissueengineered scaffolds. J Drug Target 9: 431-438, 2001.

HYUN H, KIM MS, JEONG SC, KIM YH, LEE SY, LEE HB, HYUN H, KHANG G: Preparation of diblock copolymers consisting of methoxy poly(ethylene glycol) and poly( $\varepsilon$-caprolactone)/poly(L-lactide) and their degradation property. Polym Eng Sci 46: 1242-1249, 2006.

ISHAUG SL, CRANE GM, MILLER MJ, YASKO AW, YASZEMSKI MJ, MIKOS AG: Bone formation by threedimensional stromal osteoblast culture in biodegradable polymer scaffolds. $J$ Biomed Mater Res 36: 17-28, 1997.

JAKUS AE, RUTZ AL, SHAH RN: Advancing the field of 3D biomaterial printing. Biomed Mater 11: 014102, 2016.

JENNINGS AG, SEFTON GK: Chronic rupture of tendo Achillis. Long-term results of operative management using polyester tape. J Bone Joint Surg Br 84: 361-363, 2002.

JIN R, DIJKSTRA PJ: Hydrogels for tissue engineering applications. In: Biomedical Applications of Hydrogels Handbook. OTTENBRITE RM, PARK K, OKANO T (eds.), Springer, 2010, pp. 203-226.

JÓŹWIAK AB, KIELTY CM, BLACK RA: Surface functionalization of polyurethane for the immobilization of bioactive moieties on tissue scaffolds. J Mater Chem 18: 2240-2248, 2008.

KAISER NJ, COULOMBE KLK: Physiologically inspired cardiac scaffolds for tailored in vivo function and heart regeneration. Biomed Mater 10: 034003, 2015.

KIM MS, KIM JH, MIN BH, CHUN HJ, HAN DK, LEE HB: Polymeric scaffolds for regenerative medicine. Polym Rev 51: 23-52, 2011.

KLAWITTER JJ, HULBERT SF: Application of porous ceramics for the attachment of load bearing internal orthopedic applications. J Biomed Mater Res 5: 161-229, 1971. 
LANGER R, VACANTI JP: Tissue engineering. Science 260: 920-926, 1993.

LAURILLIARD EJ, LEE KL, COOPER JA: Characterization and evaluation of fabricated poly(L-lactic) acid core fibers for ligament fascicle development. In: 2015 41st Annual Northeast Biomedical Engineering Conference (NEBEC). Institute of Electrical and Electronics Engineers, Troy, 2015, pp. 1-2.

LEE KY, MOONEY DJ: Hydrogels for tissue engineering. Chem Rev 101: 1869-1879, 2001.

LEE WK, ICHI T, OOYA T, YAMAMOTO T, KATOH M, YUI N: Novel poly(ethylene glycol) scaffolds crosslinked by hydrolyzable polyrotaxane for cartilage tissue engineering. J Biomed Mater Res A 67: 1087-1092, 2003.

LEIPZIG ND, SHOICHET MS: The effect of substrate stiffness on adult neural stem cell behavior. Biomaterials 30: 6867-6878, 2009.

LI WJ, LAURENCIN CT, CATERSON EJ, TUAN RS, KO FK: Electrospun nanofibrous structure: A novel scaffold for tissue engineering. J Biomed Mater Res 60: 613-621, 2002.

LIU M, ZENG X, MA C, YI H, ALI Z, MOU X, LI S, DENG Y, HE N: Injectable hydrogels for cartilage and bone tissue engineering. Bone Res 5: 17014, 2017.

DE LUCA AC, LACOUR SP, RAFFOUL W, DI SUMMA PG: Extracellular matrix components in peripheral nerve repair: How to affect neural cellular response and nerve regeneration? Neural Regen Res 9: 1943-1948, 2014.

MA Z, KOTAKI M, YONG T, HE W, RAMAKRISHNA S: Surface engineering of electrospun polyethylene terephthalate (PET) nanofibers towards development of a new material for blood vessel engineering. Biomaterials 26: 2527-2536, 2005.

MALIKMAMMADOV E, TANIR TE, KIZILTAY A, HASIRCI V, HASIRCI N: PCL and PCL-based materials in biomedical applications. J Biomater Sci Polym Ed 29: 863-893, 2018.

MASUDA S, SHIMIZU T, YAMATO M, OKANO T: Cell sheet engineering for heart tissue repair. Adv Drug Deliv Rev 60: 277-285, 2008.

MORAN JM, PAZZANO D, BONASSAR LJ: Characterization of polylactic acid-polyglycolic acid composites for cartilage tissue engineering. Tissue Eng 9: 63-70, 2003.

MURPHY SV, ATALA A: 3D bioprinting of tissues and organs. Nat Biotechnol 32: 773-785, 2014.

NAIR L, LAURENCIN CT: Biodegradable polymers as biomaterials. Prog Polym Sci 32: 762-798, 2007.

NAU T, TEUSCHL A: Regeneration of the anterior cruciate ligament: Current strategies in tissue engineering. World J Orthop 6: 127-136, 2015.

NAYAK R, PADHYE R, KYRATZIS IL, TRUONG YB, ARNOLD L: Recent advances in nanofibre fabrication techniques. Text Res $J$ 82: 129-147, 2012.

NECTOW AR, MARRA KG, KAPLAN DL: Biomaterials for the development of peripheral nerve guidance conduits. Tissue Eng Part B Rev 18: 40-50, 2012.

NIKOLOVSKI J, MOONEY DJ: Smooth muscle cell adhesion to tissue engineering scaffolds. Biomaterials 21: 2025-2032, 2000.

OKADA M: Chemical syntheses of biodegradable polymers. Prog Polym Sci 27: 87-133, 2002.

OSSENDORF C, KAPS C, KREUZ PC, BURMESTER GR, SITTINGER M, ERGGELET C: Treatment of posttraumatic and focal osteoarthritic cartilage defects of the knee with autologous polymer-based threedimensional chondrocyte grafts: 2-year clinical results. Arthritis Res Ther 9: R41, 2007.

PAKULSKA MM, BALLIOS BG, SHOICHET MS: Injectable hydrogels for central nervous system therapy. Biomed Mater 7: 024101, 2012.

PEI B, WANG W, FAN Y, WANG X, WATARI F, LI X: Fiber-reinforced scaffolds in soft tissue engineering. Regen Biomater 4: 257-268, 2017.

PETROVIĆ ZS, FERGUSON J: Polyurethane elastomers. Prog Polym Sci 16: 695-836, 1991.

POPELKA Š, STUDENOVSKÁ H, ABELOVÁ L, ARDAN T, STUDENÝ P, STRAŇÁK Z, KLÍMA J, DVOŘÁNKOVÁ B, KOTEK J, HODAN J, RYPÁČEK F: A frame-supported ultrathin electrospun polymer membrane for transplantation of retinal pigment epithelial cells. Biomed Mater 10: 045022, 2015.

PUSKAS JE, CHEN Y: Biomedical application of commercial polymers and novel polyisobutylene-based thermoplastic elastomers for soft tissue replacement. Biomacromolecules 5: 1141-1154, 2004.

RAMAKRISHNA S, MAYER J, WINTERMANTEL E, LEONG KW: Biomedical applications of polymer-composite materials: a review. Compos Sci Technol 61: 1189-1224, 2001. 
RENGIER F, MEHNDIRATTA A, VON TENGG-KOBLIGK H, ZECHMANN CM, UNTERHINNINGHOFEN R, KAUCZOR HU, GIESEL FL: 3D printing based on imaging data: Review of medical applications. Int J Comput Assist Radiol Surg 5: 335-341, 2010.

SAHOO S, TOH SL, GOH JCH: A bFGF-releasing silk/PLGA-based biohybrid scaffold for ligament/tendon tissue engineering using mesenchymal progenitor cells. Biomaterials 31: 2990-2998, 2010.

DE SANTIS R, SARRACINO F, MOLLICA F, NETTI PA, AMBROSIO L, NICOLAIS L: Continuous fibre reinforced polymers as connective tissue replacement. Compos Sci Technol 64: 861-871, 2004.

SATO T, CHEN G, USHIDA T, ISHII T, OCHIAI N, TATEISHI T, TANAKA J: Evaluation of PLLA-collagen hybrid sponge as a scaffold for cartilage tissue engineering. Mater Sci Eng C 24: 365-372, 2004.

EL SAYED K, MARZAHN U, JOHN T, HOYER M, ZREIQAT H, WITTHUHN A, KOHL B, HAISCH A, SCHULZE-TANZIL G: PGA-associated heterotopic chondrocyte cocultures: Implications of nasoseptal and auricular chondrocytes in articular cartilage repair. J Tissue Eng Regen Med 7: 61-72, 2013.

SCHEIB J, HÖKE A: Advances in peripheral nerve regeneration. Nat Rev Neurol 9: 668-676, 2013.

SCHLOSSHAUER B, DREESMANN L, SCHALLER HE, SINIS N: Synthetic nerve guide implants in humans: a comprehensive survey. Neurosurgery 59: 740-747, 2006.

SEDAGHATI T, YANG SY, MOSAHEBI A, ALAVIJEH MS, SEIFALIAN AM: Nerve regeneration with aid of nanotechnology and cellular engineering. Biotechnol Appl Biochem 58: 288-300, 2011.

SERENA E, FLAIBANI M, CARNIO S, BOLDRIN L, VITIELLO L, DE COPPI P, ELVASSORE N: Electrophysiologic stimulation improves myogenic potential of muscle precursor cells grown in a $3 \mathrm{D}$ collagen scaffold. Neurol Res 30: 207-214, 2008.

SHIMAO M: Biodegradation of plastics. Curr Opin Biotechnol 12: 242-247, 2001.

SIRC J, HRIB J, VETRIK M, HOBZOVA R, ZAK A, STANKOVA B, SLANAR O, HROMADKA R, SANDRIKOVA V, MICHALEK J: The use of a hydrogel matrix for controlled delivery of niacin to the gastrointestinal tract for treatment of hyperlipidemia. Physiol Res 64 (Suppl 1): S51-S60, 2015.

STRALEY KS, FOO CWP, HEILSHORN SC: Biomaterial design strategies for the treatment of spinal cord injuries. J Neurotrauma 27: 1-19, 2010.

STRATTON S, SHELKE NB, HOSHINO K, RUDRAIAH S, KUMBAR SG: Bioactive polymeric scaffolds for tissue engineering. Bioact Mater 1: 93-108, 2016.

SUBBIAH T, BHAT GS, TOCK RW, PARAMESWARAN S, RAMKUMAR SS: Electrospinning of nanofibers. J Appl Polym Sci 96: 557-569, 2005.

TAN H, MARRA KG: Injectable, biodegradable hydrogels for tissue engineering applications. Materials (Basel) 3: 1746-1767, 2010.

TSAI EC, DALTON PD, SHOICHET MS, TATOR CH: Matrix inclusion within synthetic hydrogel guidance channels improves specific supraspinal and local axonal regeneration after complete spinal cord transection. Biomaterials 27: 519-533, 2006.

VENUGOPAL J, MA LL, YONG T, RAMAKRISHNA S: In vitro study of smooth muscle cells on polycaprolactone and collagen nanofibrous matrices. Cell Biol Int 29: 861-867, 2005.

WEGST UGK, ASHBY MF: The mechanical efficiency of natural materials. Philos Mag 84: 2167-2186, 2004.

WHANG K, HEALY KE, ELENZ DR, NAM EK, TSAI DC, THOMAS CH, NUBER GW, GLORIEUX FH, TRAVERS R, SPRAGUE SM: Engineering bone regeneration with bioabsorbable scaffolds with novel microarchitecture. Tissue Eng 5: 35-51, 1999.

WOERLY S, PINET E, DE ROBERTIS L, BOUSMINA M, LAROCHE G, ROITBACKT T, VARGOVÁL L, SYKOVÁ E: Heterogeneous PHPMA hydrogels for tissue repair and axonal regeneration in the injured spinal cord. J Biomater Sci Polym Ed 9: 681-711, 1998.

WOERLY S, PETROV P, SYKOVÁ E, ROITBAK T, SIMONOVÁ Z, HARVEY AR: Neural tissue formation within porous hydrogels implanted in brain and spinal cord lesions: ultrastructural, immunohistochemical, and diffusion studies. Tissue Eng 5: 467-488, 1999.

XIE J, MACEWAN MR, LIU W, JESURAJ N, LI X, HUNTER D, XIA Y: Nerve guidance conduits based on doublelayered scaffolds of electrospun nanofibers for repairing the peripheral nervous system. ACS Appl Mater Interfaces 6: 9472-9480, 2014. 
XU H, CAI S, SELLERS A, YANG Y: Electrospun ultrafine fibrous wheat glutenin scaffolds with three-dimensionally random organization and water stability for soft tissue engineering. J Biotechnol 184: 179-86, 2014.

YANG G, ROTHRAUFF BB, TUAN RS: Tendon and ligament regeneration and repair: clinical relevance and developmental paradigm. Birth Defects Res C Embryo Today 99: 203-222, 2013.

YANG S, LEONG KF, DU Z, CHUA CK: The design of scaffolds for use in tissue engineering. Part I. Traditional factors. Tissue Eng 7: 679-689, 2001.

YE WP, DU FS, JIN WH, YANG JY, XU Y: In vitro degradation of poly(caprolactone), poly(lactide) and their block copolymers: Influence of composition, temperature and morphology. React Funct Polym 32: 161-168, 1997.

YOO HS, KIM TG, PARK TG: Surface-functionalized electrospun nanofibers for tissue engineering and drug delivery. Adv Drug Deliv Rev 61:1033-1042, 2009.

YOSHII T, HAFEMAN AE, ESPARZA JM, OKAWA A, GUTIERREZ G, GUELCHER SA: Local injection of lovastatin in biodegradable polyurethane scaffolds enhances bone regeneration in a critical-sized segmental defect in rat femora. J Tissue Eng Regen Med 8: 589-595, 2014.

ZHU J, MARCHANT RE: Design properties of hydrogel tissue-engineering scaffolds. Expert Rev Med Devices 8: 607-626, 2011. 